\title{
Influence of Various Sol-Gel Parameters on the Physico-Chemical Properties of Sulfuric Acid Chelated Zirconia Aerogels Dried at Ambient Pressure
}

\author{
Uzma K. H. Bangi, * Bhushan Patil, Rajendra C. Pawar, and Hyung-Ho Park
}

This work represents the influence of various sol-gel parameters on the physico-chemical properties of sulfuric acid chelated zirconia aerogels dried at ambient pressure. The sol-gel parameters such as concentrations of precursor, chelating agent and catalyst are found to be the dominant factors which influence the physical, chemical and textural properties of the aerogels. Therefore, the influence of concentration of $\mathrm{Zr}$ precursor, $\mathrm{ZrPr}: \mathrm{H}_{2} \mathrm{SO}_{4}$ molar ratio and $\mathrm{ZrPr}: \mathrm{H}_{2} \mathrm{O}$ molar ratio on these properties of zirconia aerogels is studied. Zirconia lacogels are formed by the hydrolysis and condensation of zirconium n-propoxide in n-propanol chelated with sulfuric acid (18.4 M) and catalyzed with deionized water. Aerogels are obtained by subsequent solvent exchange, silylation, washing and ambient pressure drying. The physico-chemical properties of as synthesized zirconia aerogels are carried out using FESEM, EDS, BET analysis and FTIR spectroscopy. The good quality zirconia aerogels are obtained using the molar ratio of

ZrPr:PrOH: $\mathrm{H}_{2} \mathrm{SO}_{4}: \mathrm{H}_{2} \mathrm{O}: \mathrm{HMDZ}: 1: 2.93: 1.18: 1.77: 0.59$. They possess the density of $0.54 \mathrm{~g} \mathrm{~cm}^{-3}$, BET surface area of $328 \mathrm{~m}^{2} \mathrm{~g}^{-1}$ and micropore volume of $0.028 \mathrm{~cm}^{3} \mathrm{~g}^{-1}$. These aerogels can be applied as heterogeneous catalysts in many fields. surface area etc. ${ }^{[1,2]}$ They are attracting due to their potential applications in catalysis, thermal insulation, oil spill cleanup, sensors and space technology etc. ${ }^{[3,4]}$ Wide variety of the aerogels have been synthesized such as silica, metal oxide (alumina, titania, zirconia) as well as transition metal oxide aerogels, etc., for different purposes. These aerogels were synthesized by the conventional methods of supercritical drying and freeze drying. However, this conventional way of aerogels synthesis is expensive and energy intensive due to sophisticated techniques, which partly restricts their commercialization. Among all these aerogels, zirconia aerogels have found to be outstanding owing to its acidic/basic character, oxidizing/reducing chemical properties as well as good textural characteristics which help to enhance the catalytic activity, thermal stability, and resistance to poisoning. ${ }^{[5]}$ The catalytic applications of zirconia aerogels related to the modification of their surfaces by copper, iron, sulfate, phosphate, etc. and use of surfactant like

\section{Introduction}

Aerogels are the versatile materials which combine the properties of being highly divided solids with their metastable character. They possess the extraordinary properties such as low density, low thermal conductivity, high porosity as well as large

U. K. H. Bangi

School of Physical Sciences

Solapur University, Solapur-Pune National Highway, Kegaon

Solapur, Maharashtra 413 255, India

E-mail: uzma.phys@gmail.com

B. Patil

Institute of Material Science and Nanotechnology, National

Nanotechnology Research Center (UNAM)

Bilkent University

Ankara 06800, Turkey

R. C. Pawar

State Key Laboratory of Catalysis

Dalian Institute of Chemical Physics, Chinese Academy of Sciences

Dalian 116023, China

H.-H. Park

Department of Materials Science and Engineering

Yonsei University

Seoul 120-749, Republic of Korea

DOI: 10.1002/masy.202000025 cetyl trimethyl ammonium bromide (CTAB), octyl trimethyl ammonium bromide (OTAB), etc. have been reported. The zirconia aerogels were employed as a catalyst for the dehydration of methylpentan-2-ol reaction, $\mathrm{CO}=\mathrm{CO}_{2}$ hydrogenation and isomerization of $n$-hexane reaction. ${ }^{[6-8]}$ Despite a number of excellent papers on their preparation based on the supercritical drying method, ${ }^{[9,10]}$ more focus is necessary on the synthesis of zirconia aerogels via ambient pressure drying. There are a few numbers of reports on the synthesis of ambient pressure dried zirconia aerogels. ${ }^{[11-13]}$ Therefore, in the present work attempts were focused to synthesize zirconia aerogels via ambient pressure drying method. Moreover, the influence of various sol-gel parameters such as concentration of zirconia precursor, chelating agent and catalyst on the physico-chemical properties of zirconia aerogels was studied.

\section{Results and Discussion}

\subsection{Influence of the $\mathrm{Zr}$ Precursor Concentrations}

The influence of varying concentrations of zirconium propoxide $(\mathrm{ZrPr})$ on the volume and density of zirconia aerogels is shown in Figure 1. During the preparation of alcogels the molar ratio 


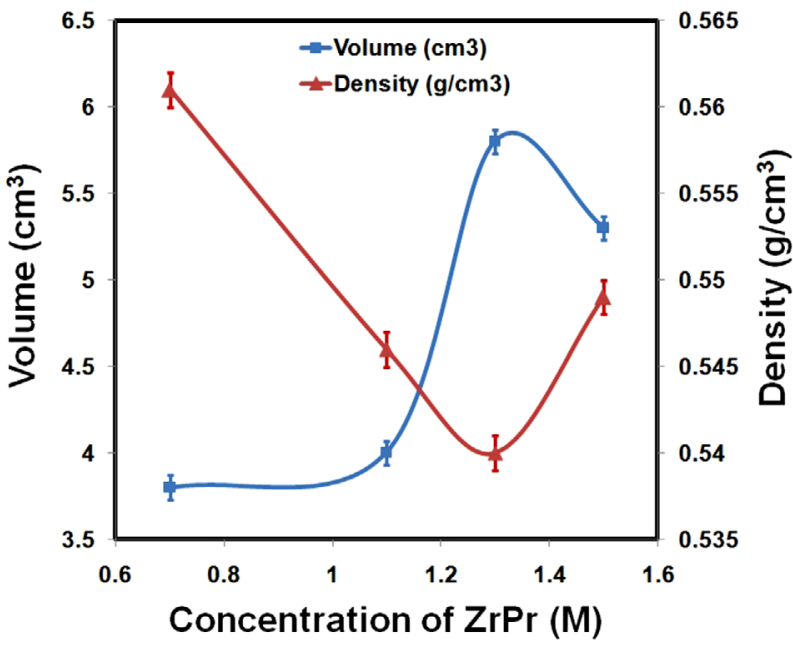

Figure 1. Influence of varying $\mathrm{ZrPr}$ concentrations on volume and density of the zirconia aerogels.

of $\mathrm{H}_{2} \mathrm{SO}_{4}: \mathrm{H}_{2} \mathrm{O}: \mathrm{HMDZ}$ was kept fix for 1:17.8:5.94. As seen from Figure 1, the obtained volume of the zirconia aerogels is low for lower concentration of $\operatorname{ZrPr}(<1.3 \mathrm{M})$. The volume of aerogels increased for $\mathrm{ZrPr}$ concentration of $1.3 \mathrm{M}$ and then decreased for higher concentration $(>1.3 \mathrm{M})$. The reason behind this may be, at lower $\mathrm{ZrPr}$ concentration the lower zirconia content in the alcosol weakens the zirconia network. This causes the shrinkage during the drying process leading to the lower volume of aerogels. The bulk density of the zirconia aerogels is higher because of lower volume of the aerogels which is due to lower $\mathrm{ZrPr}$ concentration $(<1.3 \mathrm{M})$. At higher values of $\mathrm{ZrPr}$ concentration $(>1.3$ $\mathrm{M})$, the higher zirconia content in alcosol may cause the cluster formation leading to higher zirconia content per unit volume, i.e., denser aerogels were obtained. Such variation in the density of zirconia aerogels due to variation in $\mathrm{ZrPr}$ is same as that of the variations in the density of silica aerogels with concentration of sodium silicate as reported by elsewhere. ${ }^{[14]}$ The ZrPr concentration of $1.3 \mathrm{M}$ produced the aerogels with higher volume and lower density of nearly $5.8 \mathrm{~cm}^{3}$ and $0.540 \mathrm{~g} \mathrm{~cm}^{-3}$, respectively compared to all other samples. Therefore, for further experiments the concentration of $\mathrm{ZrPr}$ was taken fix as $1.3 \mathrm{M}$.

\subsection{Influence of $\mathrm{ZrPr}: \mathrm{H}_{2} \mathrm{SO}_{4}$ Molar Ratios}

The influence of different concentrations of chelating agent $\left(\mathrm{H}_{2} \mathrm{SO}_{4}\right)$ on the properties of zirconia aerogels was studied by varying the molar ratios of $\mathrm{ZrPr}: \mathrm{H}_{2} \mathrm{SO}_{4}$ from 2.5 to 10.02. During the zirconia alcogel formation the molar ratio of ZrPr:PrOH: $\mathrm{H}_{2} \mathrm{O}: \mathrm{HMDZ}$ was kept fix for 1:2.93:1.77:0.593. Figure 2 shows the photographs of zirconia alcogels formed without $\mathrm{H}_{2} \mathrm{SO}_{4}$ (Figure 2a) and with varying molar ratios of $\mathrm{ZrPr}: \mathrm{H}_{2} \mathrm{SO}_{4}$ (Figure $2 \mathrm{~b}$ and c). As seen from Figure 2, the zirconia alcogel prepared without $\mathrm{H}_{2} \mathrm{SO}_{4}$ showed the zirconia particles clusters which were delicate in nature than other two alcogels prepared using $\mathrm{H}_{2} \mathrm{SO}_{4}$. Because of this reason these aerogels are very brittle and found to have lower volume $\left(2 \mathrm{~cm}^{3}\right)$. The photographs of obtained aerogels are shown in Figure 3.
The influence of varying molar ratios of $\mathrm{ZrPr}: \mathrm{H}_{2} \mathrm{SO}_{4}$ on the obtained volume and density of zirconia aerogels is represented in Figure 4. The zirconia aerogels synthesized without $\mathrm{H}_{2} \mathrm{SO}_{4}$ have low density $\left(0.446 \mathrm{~g} \mathrm{~cm}^{-3}\right)$ but they also have low volume $\left(2 \mathrm{~cm}^{3}\right)$ while the aerogels prepared using the $\mathrm{ZrPr}: \mathrm{H}_{2} \mathrm{SO}_{4}$ molar ratio of 10.01 have density nearly equal to $0.540 \mathrm{~g} \mathrm{~cm}^{-3}$ and high volume of $5.8 \mathrm{~cm}^{3}$. This may be due to the instantaneous rapid hydrolysis and improper condensation of zirconia particles in absence of $\mathrm{H}_{2} \mathrm{SO}_{4}$ which causes the breaking of bonds during drying forming the shrinked aerogels. ${ }^{[15]}$ On other hand, the presence of $\mathrm{H}_{2} \mathrm{SO}_{4}$ delayed the hydrolysis and condensation to some extent due to zirconia complex formation (Equation 1) producing the aerogels with good strength. Therefore, for further experiments the molar ratio of $\mathrm{ZrPr}: \mathrm{H}_{2} \mathrm{SO}_{4}$ was kept fix for 10.01.

The FESEM images of zirconia aerogels for different $\mathrm{ZrPr}: \mathrm{H}_{2} \mathrm{SO}_{4}$ molar ratios are shown in Figure 5. The porous morphology is observed for both the aerogels prepared using $\mathrm{ZrPr:H} \mathrm{SO}_{4}$ molar ratios of 10.01 and 5.02 (Figure 5a and b). These aerogels exhibits a well-tailored mesoporous network formation. Figure 6 depicts the EDS spectra of the zirconia aerogels for various molar ratios of $\mathrm{ZrPr}: \mathrm{H}_{2} \mathrm{SO}_{4}$. It is observed that the weight\% of sulfur increased in the aerogels with increase in the concentration of sulfur, i.e., in decrease in molar ratio of $\mathrm{ZrPr}: \mathrm{H}_{2} \mathrm{SO}_{4}$.

The $\mathrm{N}_{2}$ adsorption desorption isotherms of zirconia aerogels synthesized without $\mathrm{H}_{2} \mathrm{SO}_{4}$ and with varying molar ratios of $\mathrm{ZrPr:} \mathrm{H}_{2} \mathrm{SO}_{4}$ are presented in Figure 7. All these aerogels revealed type IV isotherms manifesting the capillary condensation that occurs in mesopores. ${ }^{[16]}$ The zirconia aerogels prepared without $\mathrm{H}_{2} \mathrm{SO}_{4}$ showed type $\mathrm{H} 1$ hysteresis (Figure 7a) manifesting well defined cylindrical pore channels. The aerogels prepared using $\mathrm{ZrPr}: \mathrm{H}_{2} \mathrm{SO}_{4}$ molar ratio of 10.01 (Figure $7 \mathrm{~b}$ ) exhibited type $\mathrm{H} 2$ hysteresis manifesting disordered pores while aerogels synthesized using $\mathrm{ZrPr}: \mathrm{H}_{2} \mathrm{SO}_{4}$ molar ratio of 5.02 (Figure 7c) illustrated $\mathrm{H} 4$ hysteresis with narrow slit pores. Among all three samples, aerogels prepared without $\mathrm{H}_{2} \mathrm{SO}_{4}$ have larger surface area $\left(349.29 \mathrm{~m}^{2} \mathrm{~g}^{-1}\right)$ due to presence of more micropores, but the obtained volume of aerogels is very low (Figure 4). The zirconia aerogels prepared using the molar ratio of $\mathrm{ZrPr}: \mathrm{H}_{2} \mathrm{SO}_{4}$ nearly 10.01 have higher volume (Figure 4) and comparable surface area of around $328 \mathrm{~m}^{2} \mathrm{~g}^{-1}$.

Figure 8 shows the FT-IR spectra of the synthesized zirconia aerogels without $\mathrm{H}_{2} \mathrm{SO}_{4}$ and using the molar ratio of $\mathrm{ZrPr}: \mathrm{H}_{2} \mathrm{SO}_{4}$ nearly 10.01 . As shown in fig. 8 the peaks at around 3340, 1560, and $1350 \mathrm{~cm}^{-1}$ correspond to the vibration of stretching, deformation and bending of the $-\mathrm{OH}$ bond due to absorbed and coordinated water respectively. ${ }^{[17]}$ The peaks at around 2860 and $2920 \mathrm{~cm}^{-1}$ are assigned to $\mathrm{C}-\mathrm{H}$ while the peak at $848 \mathrm{~cm}^{-1}$ corresponds to $\mathrm{Si}-\mathrm{C}$ bond. The presence of the absorption peak at 1260, 790, $986 \mathrm{~cm}^{-1}$ assigned to the Zr-OPr, Zr-O-Zr and Zr-O-Si respectively indicating the zirconia network formation and silylation (Equation 5). ${ }^{[11]}$ The peaks at 1060 and $1130 \mathrm{~cm}^{-1}$ in zircnia aerogels prepared using $\mathrm{H}_{2} \mathrm{SO}_{4}$ correspond to the $\mathrm{S}-\mathrm{O}$ and $\mathrm{S}=\mathrm{O}$ stretching vibrations. ${ }^{[18]}$

\subsection{Influence of $\mathrm{ZrPr}: \mathrm{H}_{2} \mathrm{O}$ Molar Ratios}

The influence of different concentrations of hydrolysis $\mathrm{H}_{2} \mathrm{O}$ on the properties of zirconia aerogels was studied by varying 

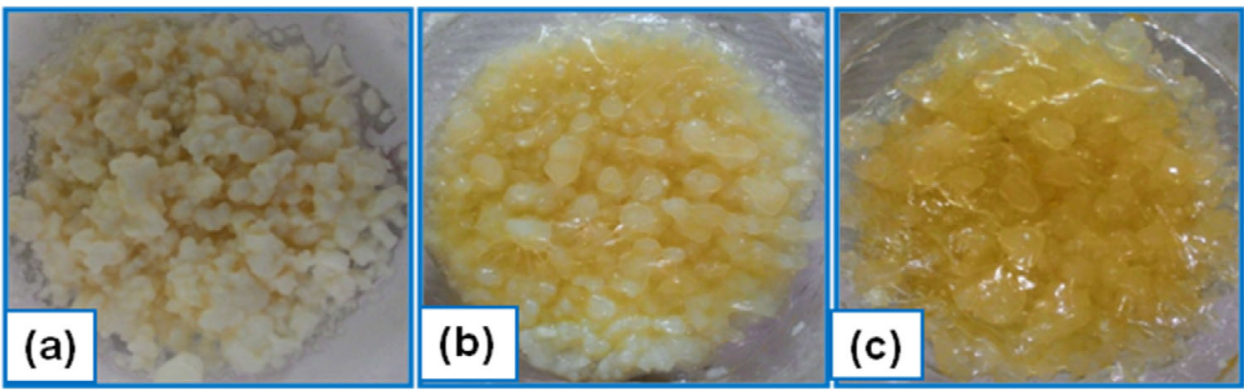

Figure 2. Photographs of zirconia alcogels a) without $\mathrm{H}_{2} \mathrm{SO}_{4}, \mathrm{~b}$ and c) with varying molar ratios of $\mathrm{ZrPr}_{\mathrm{P}} \mathrm{H}_{2} \mathrm{SO}_{4}$ b) $\left.10.02, \mathrm{c}\right) 5.02$.

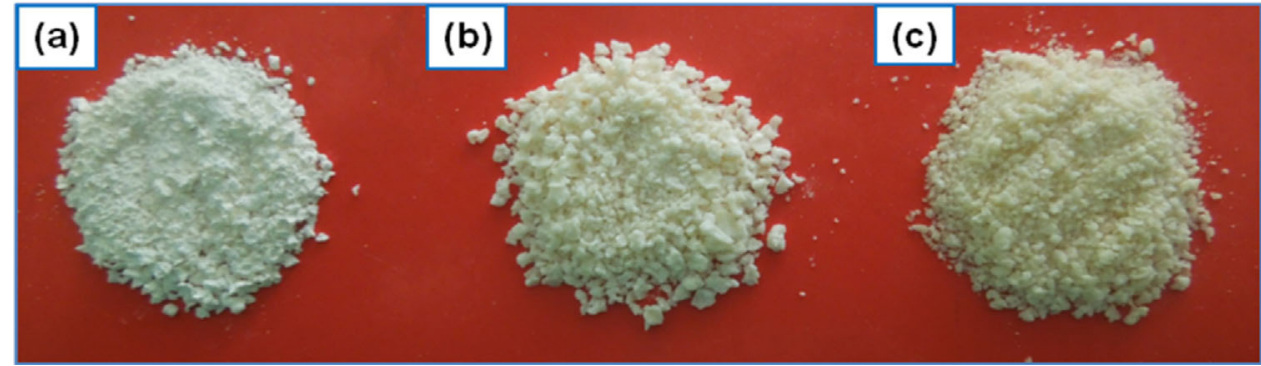

Figure 3. Photographs of zirconia aerogels a) without $\mathrm{H}_{2} \mathrm{SO}_{4}$, b and c) with varying molar ratios of $\mathrm{ZrPr}: \mathrm{H}_{2} \mathrm{SO}_{4}$ b) $\left.10.02, c\right) 5.02$.

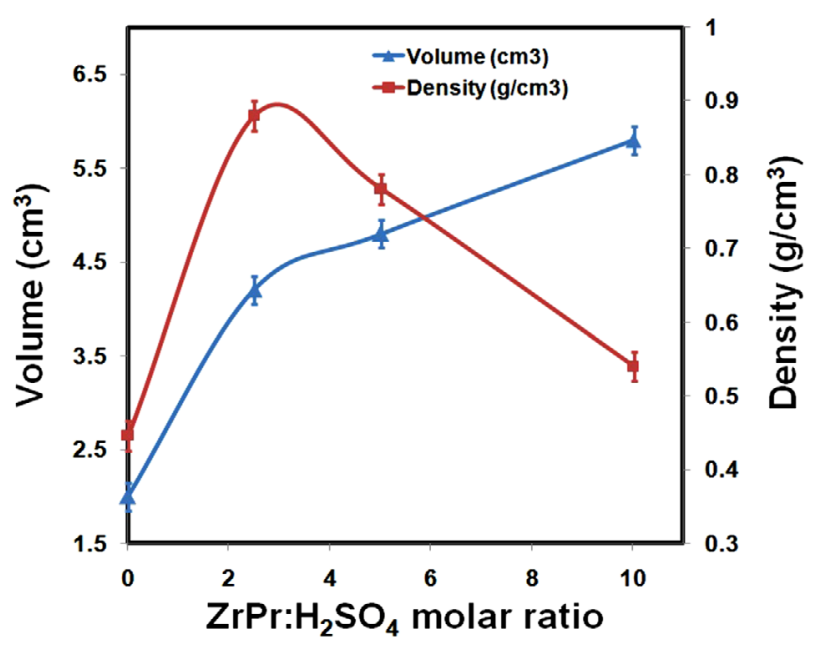

Figure 4. Influence of varying $\mathrm{ZrPr}: \mathrm{H}_{2} \mathrm{SO}_{4}$ molar ratios on volume and density of the zirconia aerogels.

molar ratios of $\mathrm{ZrPr}: \mathrm{H}_{2} \mathrm{O}$ from 0.34 to 0.56 . During the synthesis the molar ratio of $\mathrm{ZrPr}: \mathrm{PrOH}: \mathrm{H}_{2} \mathrm{SO}_{4}: \mathrm{HMDZ}$ was kept fix at 1:2.93:1.18:0.593. Figure 9 depicts the influence of $\mathrm{ZrPr}: \mathrm{H}_{2} \mathrm{O}$ molar ratios on the output volume and density of zirconia aerogels. An increase-decrease-increase behavior is observed in the volume of zirconia aerogels with the increase in $\mathrm{ZrPr}: \mathrm{H}_{2} \mathrm{O}$ molar ratio. The lower density $\left(0.45 \mathrm{~g} \mathrm{~cm}^{-3}\right)$ of aerogels is obtained for the molar ratio of $\mathrm{ZrPr}: \mathrm{H}_{2} \mathrm{O}$ of 0.42 . But, the BET surface area of these aerogels is low $\left(280 \mathrm{~m}^{2} \mathrm{~g}^{-1}\right)$ compared to the surface area $\left(328 \mathrm{~m}^{2} \mathrm{~g}^{-1}\right)$ of zirconia aerogels prepared using $\mathrm{ZrPr}: \mathrm{H}_{2} \mathrm{O}$ molar ratio of 0.56 . The reason behind this may be the use of low amount of $\mathrm{H}_{2} \mathrm{O}$ causes the sufficient and proper hydrolysis and condensation of Zr precursor (Equations 2-4). ${ }^{[11]}$ The FTIR spectra of zirconia aerogels for varying molar ratios of $\mathrm{ZrPr}: \mathrm{H}_{2} \mathrm{O}$ is shown in Figure 10. These spectra were compared and it is observed that the intensities of $\mathrm{Si}-\mathrm{C}$ and $\mathrm{Zr}-\mathrm{O}-\mathrm{Si}$ peaks increased with decrease in $\mathrm{ZrPr}: \mathrm{H}_{2} \mathrm{O}$ molar ratio. This manifests that the increased $\mathrm{H}_{2} \mathrm{O}$ quantity may help to form more zirconia particles which undergo silylation leading to higher volume and lower density (Figure 9) of aerogels.

\section{Conclusion}

Influence of various sol-gel parameters like $\mathrm{Zr}$ precursor, $\mathrm{H}_{2} \mathrm{SO}_{4}$ chelating agent and hydrolysis $\mathrm{H}_{2} \mathrm{O}$ concentrations on the physical, morphological and textural properties of ambient pressure dried zirconia aerogels was successfully studied. It was observed the $\mathrm{Zr}$ precursor concentration has profound effect on the density of aerogels. Moreover, it was found that the lower concentration of $\mathrm{H}_{2} \mathrm{SO}_{4}$ produces high volume, low density and high surface area aerogels than other aerogels (without $\mathrm{H}_{2} \mathrm{SO}_{4}$ and high concentration of $\mathrm{H}_{2} \mathrm{SO}_{4}$ ). Further, the variation in the quantity of hydrolysis $\mathrm{H}_{2} \mathrm{O}$ plays a vital role in reducing the density of aerogels. The good quality zirconia aerogels having the density of $0.54 \mathrm{~g} \mathrm{~cm}^{-3}$, BET surface area of $328 \mathrm{~m}^{2} \mathrm{~g}^{-1}$ and micropore volume of $0.028 \mathrm{~cm}^{3} \mathrm{~g}^{-1}$ were obtained using the molar ratio of $\mathrm{ZrPr}: \mathrm{PrOH}: \mathrm{H}_{2} \mathrm{SO}_{4}: \mathrm{H}_{2} \mathrm{O}: \mathrm{HMDZ}: 1: 2.93: 1.18: 1.77: 0.593$. They are applicable for heterogeneous catalysis in many fields.

\section{Experimental Section}

Materials: For the preparation of zirconia aerogels, the chemicals used were: zirconium n-propoxide $(\mathrm{ZrPr})\left(\mathrm{Zr}\left(\mathrm{OC}_{3} \mathrm{H}_{7}\right)_{4}, 70 \%\right.$ in $\mathrm{n}-\mathrm{PrOH}$, 

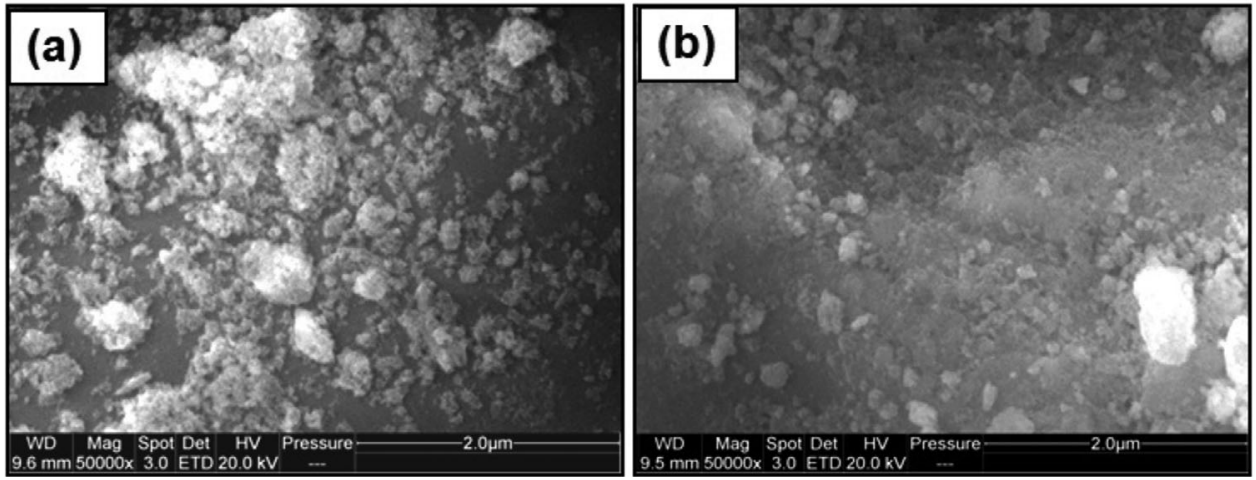

Figure 5. SEM images of the zirconia aerogels with varying molar ratios of $\mathrm{ZrPr}: \mathrm{H}_{2} \mathrm{SO}_{4}$ a) 10.01, b) 5.02 .

(a)

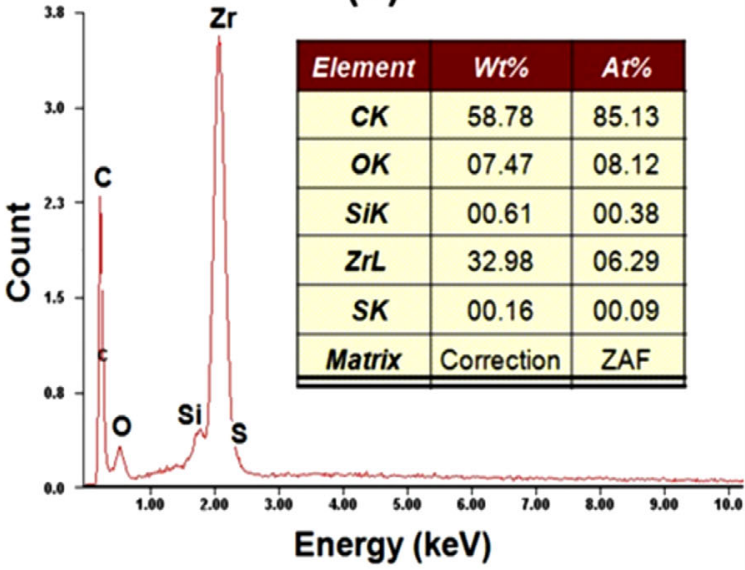

(b)

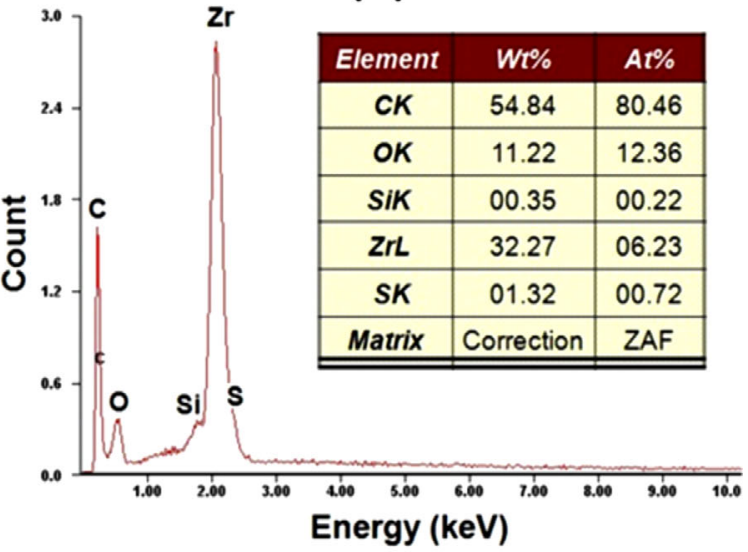

Figure 6. EDS spectra of the zirconia aerogels (inset - \% of elements) with varying molar ratios of $\mathrm{ZrPr}: \mathrm{H}_{2} \mathrm{SO}_{4}$ a) 10.01, b) 5.02 .

Sigma-Aldrich) as a precursor, n-propanol (n-PrOH, Duksan) as a solvent, sulfuric acid (18.4 M) $\left(\mathrm{H}_{2} \mathrm{SO}_{4}\right.$, SD Fine) as chelating agent, deionized water (D.I. $\mathrm{H}_{2} \mathrm{O}$ ) as a catalyst, hexamethyldisilazane (HMDZ) as silylating agent as well as ethanol (EtOH) and hexane (Hex.) (SD Fine) as exchanging solvents.

Synthesis of Aerogels: Initially, the alcogels were prepared by mixing $\mathrm{PrOH}, \mathrm{ZrPr}$ and $\mathrm{H}_{2} \mathrm{SO}_{4}$ well before the addition of catalyst. After $15 \mathrm{~min}$. stirring, D.I. $\mathrm{H}_{2} \mathrm{O}$ was added to this mixture necessary for the sol-gel process which leads to the formation alcogel. During the sol-gel process the hydrolysis and condensation reactions take place as given in reactions (1) to (4), where $\mathrm{R}$ is propyl $\left(\mathrm{C}_{3} \mathrm{H}_{7}\right)$ group.

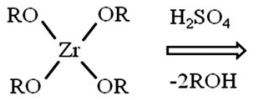<smiles>[R6][Te]1([R20])OS(=O)(=O)O1</smiles><smiles>[R6][Te]1([R20])OS(=O)(=O)O1</smiles>

rconium propoxide complex<smiles>O=S1(=O)O[Te](O)(O)O1</smiles>

Zirconium hydroxide

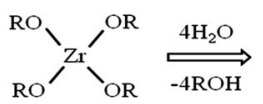<smiles>C[Z1](O)(O)O</smiles>

Zirconium hydroxide<smiles>O=S1(=O)O[Z](O)(O)O[Te]1(O)O[Te]1(O)O[Te](O)(O)O1</smiles>

Afterwards, alcogels were aged in PID controlled oven at $50^{\circ} \mathrm{C}$ for $3 \mathrm{~h}$ The solvent of these alcogels was exchanged out immersing them in (i) mixture of $\mathrm{PrOH}$ and $\mathrm{EtOH}$, (ii) $\mathrm{EtOH}$, (iii) mixture of $\mathrm{EtOH}$ and $\mathrm{Hex}$, (iv) Hex for $1 \mathrm{~h}$ each. The silylation or surface modification of these solvent exchanged alcogels were simultaneously done using the mixture of HMDZ (15\%) and Hex (85\%) for $1 \mathrm{~h}$ as shown in reaction (5).

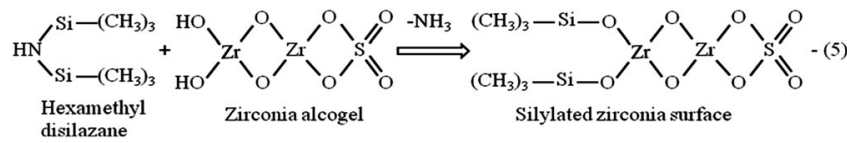

The silylated hexagels were again washed with Hex. to remove the unreacted HMDZ and byproducts of the reaction. The solvent exchange, silylation and washing were performed by shaking the immersed alcogels in the orbital shaker at $50^{\circ} \mathrm{C}$. Finally, the drying was carried out by putting the washed silylated hexagels in PID controlled oven at $50^{\circ} \mathrm{C}(1 \mathrm{~h})$ and then increasing the temperature to $200{ }^{\circ} \mathrm{C}(1 \mathrm{~h})$. The obtained aerogels were used for the characterizations after cooling of the oven to room temperature. Influence of sol-gel parameters on the properties of zirconia aerogels was studied by varying the concentration of $\mathrm{Zr}$ precursor, the molar ratios of $\mathrm{ZrPr}: \mathrm{H}_{2} \mathrm{SO}_{4}$ and $\mathrm{ZrPr}: \mathrm{H}_{2} \mathrm{O}$.

Characterizations: The density of aerogels was calculated using the ratio of weight and volume of aerogels. The weights of aerogels were measured using the analytical balance $\left(10^{-5}\right.$ accuracy, CONTECH) and volumes using the glass cylinder of known volume. The morphological and elemental analyses of the aerogels were carried out by utilizing field emission scanning electron microscopy (Quanta 220F, FEI). The surface area and micropore volume of the zirconia aerogels were measured by 


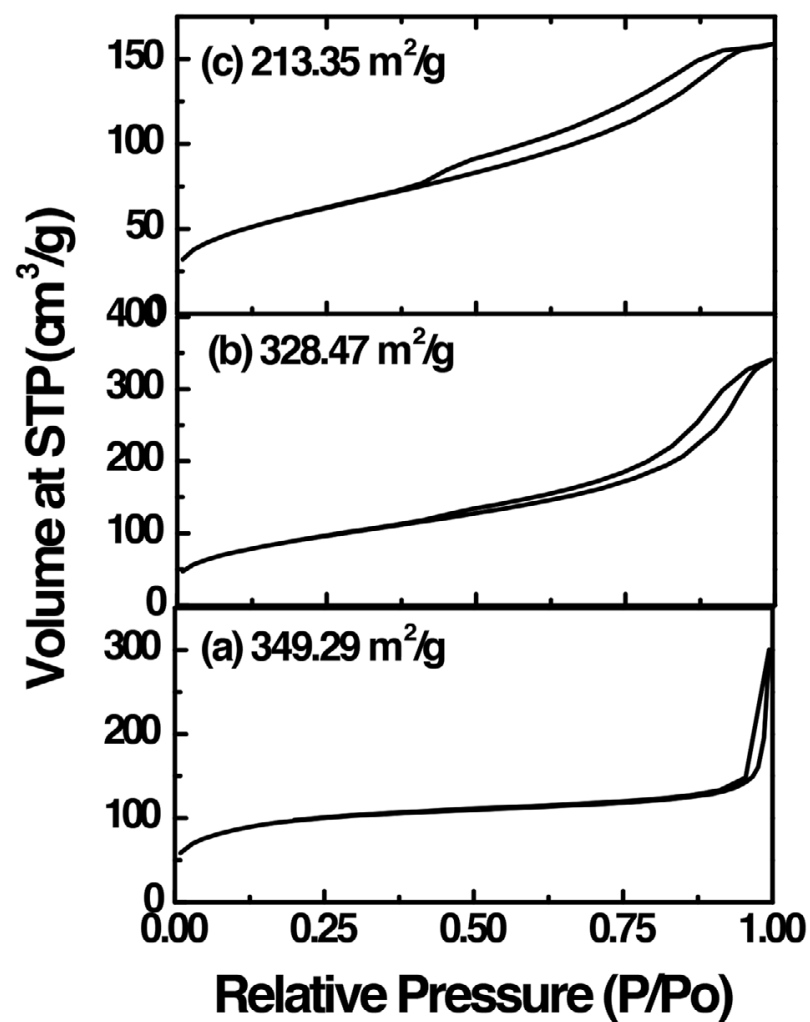

Figure 7. $\mathrm{N}_{2}$ adsorption desorption isotherms of the zirconia aerogels a) without $\mathrm{H}_{2} \mathrm{SO}_{4}, \mathrm{~b}$ and c) with various $\mathrm{ZrPr}: \mathrm{H}_{2} \mathrm{SO}_{4}$ molar ratios b) 10.01, c) 5.02 .

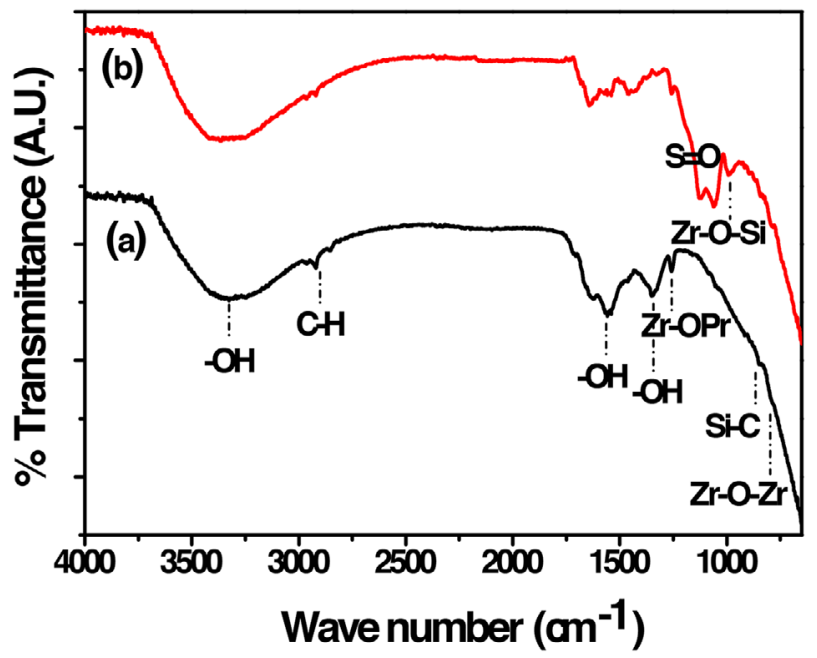

Figure 8. FTIR spectra of the zirconia aerogels a) without $\mathrm{H}_{2} \mathrm{SO}_{4}$, b) with $\mathrm{ZrPr}: \mathrm{H}_{2} \mathrm{SO}_{4}$ molar ratio of 10.01 .

applying $\mathrm{N}_{2}$ adsorption desorption analysis (Quantachrome $\mathbb{R}$ ASiQwin ${ }^{\mathrm{TM}}$ ). Fourier transform infrared spectroscopy (FT-IR, Thermo Scientific, USA) was employed for the identification of the chemical bonds present in the zirconia aerogels.

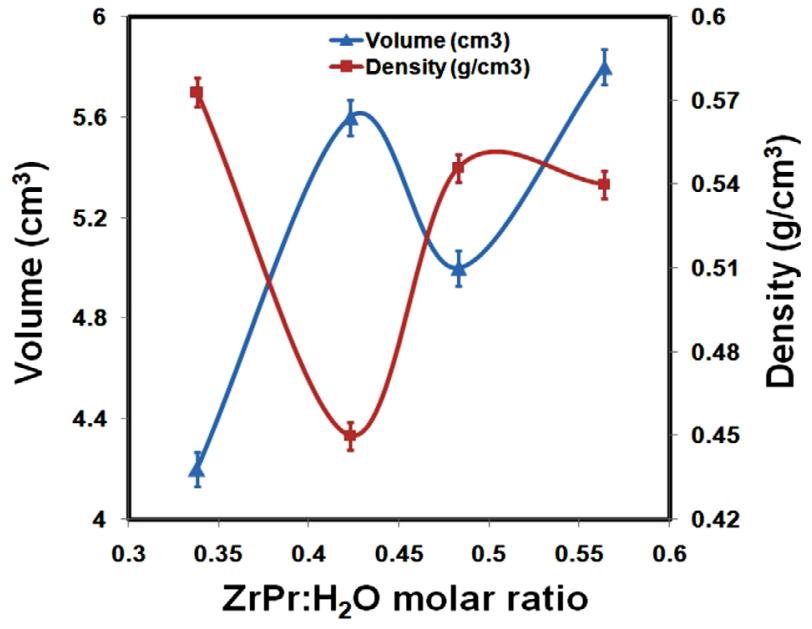

Figure 9. Influence of varying $\mathrm{ZrPr}: \mathrm{H}_{2} \mathrm{O}$ molar ratios on volume and density of the zirconia aerogels.

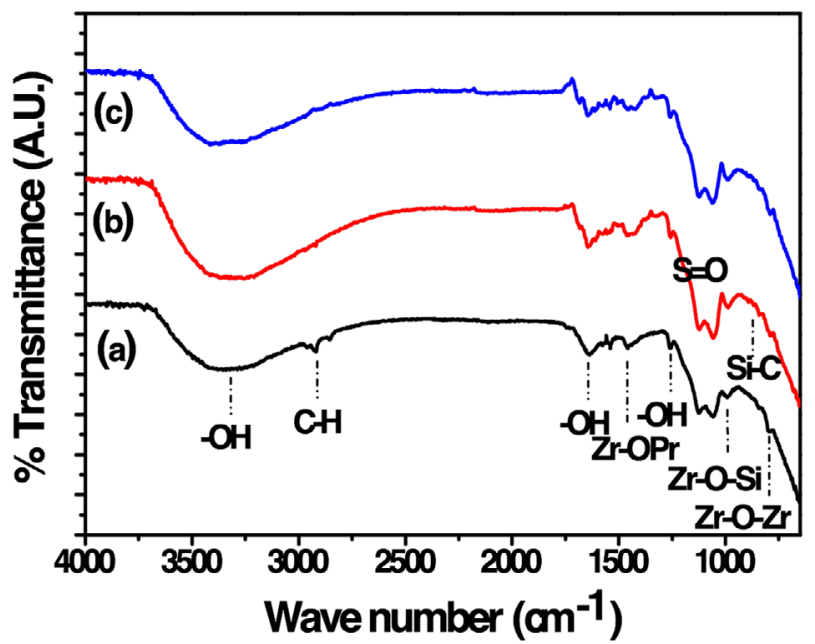

Figure 10. FTIR spectra of the zirconia aerogels with varying molar ratios of $\mathrm{ZrPr}: \mathrm{H}_{2} \mathrm{O}$ (a) 0.483 , (b) 0.423 , (c) 0.338 .

\section{Acknowledgements}

This study was financially supported by the Department of Science and Technology-Science \& Engineering Research Board (DST-SERB), New Delhi, India, through a major research project on "aerogels" (no. SB/FTP/PS-030/2014).

\section{Conflict of Interest}

The authors declare no conflict of interest.

\section{Keywords}

ambient pressure drying, BET surface area, chelating agent, Sol-gel, zirconia aerogels 
[1] A. V. Rao, M. M. Kulkarni, Mater. Res. Bull. 2002, 37, 1667.

[2] V. G. Parale, K.-Y. Lee, H.-H. O. Park, J. Korean Ceramic Soc. 2017, 54 184.

[3] A. V. Rao, N. D. Hegde, H. Hirashima, J. Colloid Interface Sci. 2007, 305, 124

[4] M. K. Carroll, A. M. Anderson, in Aerogels Handbook, (Eds: M. A. Aegerter, N. Leventis, M. M. Koebel), Springer, New York 2011.

[5] L. Hammouda, I. Mejri, M. Younes, A. Ghorbel, in Aerogels handbook, (Eds: Agerter, M., Prassas, M.), Springer, Heidelberg 2012 p. pp. 127.

[6] I. Ferino, M. Casula, A. Corrias, M. F. Casula, A. Corrias, M. G. Cutrufello, R. Monaci, G. Paschina, Phys. Chem. Chem. Phys. 2000, 2, 1847.

[7] Y. Suh, H. Rhee, S. Moon, Catal. Today 2000, 63, 447.

[8] I. Mejri, M. Younes, A. Ghorbel, Stud. Surf. Sci. Catal. 2008, 174, 493.

[9] Y. Cao, J. C. Hu, Z. S. Hong, J. F. Deng, K. N. Fan, Catal. Lett. 2002, 81, 107.
[10] R. Sui, A. S. Rizkalla, P. A. Charpentier, Langmuir 2006, 22, 4390.

[11] U. K. H. Bangi, C. S. Park, S. Baek, H. H. Park, Powder Technol. 2013, 239, 314.

[12] H. N. R. Jung, W. Han, H. H. Cho, H. H. Park, Mater. Express 2017, 7, 291.

[13] U. K. H. Bangi, H. H. Park, International. Nano Letters 2018, 8, 221.

[14] U. K. H. Bangi, S. S. Pandit, D. B. Bagal, H. H. Park, Macromolecular Symposia 2019, 387, 1800226

[15] C. Viazzi, A. Deboni, C. Viazzia, A. Debonib, J. Z. Ferreirab, J.-P. Boninoa, F. Ansarta, Solid State Sci. 2006, 8, 1023.

[16] K. S. W. Sing, D. H. Everett, R. A. W. Haul, L. Moscou, R. A. Pierotti, J. Rouquerol, T. Siemieniewska, Pure Appl. Chemistry 1985, 57, 603.

[17] A. Hezam, K. Namratha, Q. A. Drmosh, B. N. Chandrashekar, K. K. Sadasivuni, Z. H. Yamani, C. Cheng, K. Byrappa, Cryst. Eng. Comm. 2017, 19, 3299.

[18] A. Rachmat, W. Trisunaaryanti, Sutarno, K. Wijaya, Mater. Renew. Sustain Energy 2017, 6, 13. 